\title{
Seismic Design of Magneto-Rheological Dampers between Different Sizes Buildings under Optimum Parameters
}

\author{
Mehmet Eren Uz \\ Lecturer, Deptartment of Civil Engineering, Adnan Menderes University, Aydin, PK 09100, Turkey \\ mehmet.uz@adu.edu.tr \\ Received: $6^{\text {th }}$ November 2016 \\ Accepted: $26^{\text {th }}$ December 2016 \\ DOI: http://dx.doi.org/10.18466/cbujos.281551
}

\begin{abstract}
The effectiveness of optimal semi-active dampers for reaching the optimum gains of the response of the adjacent buildings connected by magneto-rheological (MR) dampers subjected to seismic motion is examined in this study. One of the challenges is to improve an effective optimal control strategy, utilizing the capabilities of the MR dampers. Hence, a SIMULINK block in MATLAB program was developed to compute the desired control forces at each floor level and to the obtain number of dampers. Linear quadratic regulator (LQR) and linear quadratic Gaussian (LQG) controllers are used for achieving the desired control forces, whilst the desired voltage is synthesized based on clipped voltage law (CVL). The control objective is to diminish both the displacement and acceleration responses. As a result, MR dampers can deliver noteworthy displacement response control that is possible with less voltage for the shorter building.
\end{abstract}

Keywords - Adjacent buildings, clipped optimal algorithm, Magneto-Rheological (MR) damper, seismic effects, Semi-active control

\section{Introduction}

Various control devices have been widely utilized as supplemental damping strategies in order to mitigate the effects of earthquakes and high wind load on civil engineering structures. Dampers have been used onto structures as paramount interest over the past two decades. These dampers include fluid visco-elastic dampers [1-4], friction dampers [1-4], active devices [5-8] and semi-active magnetorheological (MR) dampers [9-12]. Westermo [13] was the first to propose the concept of linking the podium structure to the main buildings for avoiding the pounding effects. Westermo [13] found that this concept can be applied to mitigate the problem of pounding between the podium structure and the main building. Ni et al. [14] and Yoshida and Dyke [15] have researched about how the magnetorheological (MR) dampers can work on structures. Although semi-active control is still new as a recent development, some authors are still continuing to work on passive and active structural control [15].
Optimizing the use of dampers to mitigate seismic damage has hitherto not been investigated in spite of enhancing structural control concepts in the structural vibration control through the application of optimization. Luco and De Barros [16] found the optimal damping parameters for the distribution of passive dampers. In general, analytical and experimental studies have investigated the seismic responses of the structures before and after installing a damping device to understand their effectiveness. However, very few studies have been undertaken regarding the effect of non-uniform distribution of the dampers $[1,5,17$ 18]. None of these studies show a clear comparison in order to indicate the quality of their own proposed arrangement/solution. For example, Bhaskararao and Jangid [5] proposed a parametric study to examine the optimum slip force of the dampers in the responses of two adjacent structures. The authors also found that the optimum placement of damper helps the response reduction.

In order to improve other recent strategies, the existed control algorithms on passive, semiactive and active control can be used. Linear 
Quadratic Regulator (LQR), $\mathrm{H}_{2} / \mathrm{LQG}$ (Linear Quadratic Gaussian), $H_{2}, H_{\infty}$ and fuzzy control can be selected as the existed optimal control algorithms. Ahlawat and Ramaswamy [19] used a multi-objective of the GA in order to provide an optimum solution in damper design. Despite of the simplicity of a passive control, semi-active and active control systems are currently getting more attention. Arfiadi and Hadi [20] developed a simple optimization technique using genetic algorithms (GA) to measure the force for the control. A inactive output was used with the help of the measurement output in their study for feedback controller. Two optimization controls were used by the authors to compare their controllers' performance. The aim is to obtain the optimum controller for MR dampers by using LQR and $H_{2} / L Q G$ strategies. The uncontrolled individual buildings responses are compared with the corresponding numerical results of adjacent buildings controlled with MR dampers using nonlinear control algorithms.

\section{System Model}

Consider semi-active dampers placed throughout two $\mathrm{n}$ and $\mathrm{m}$ storey structures with as shown in Figure 1.

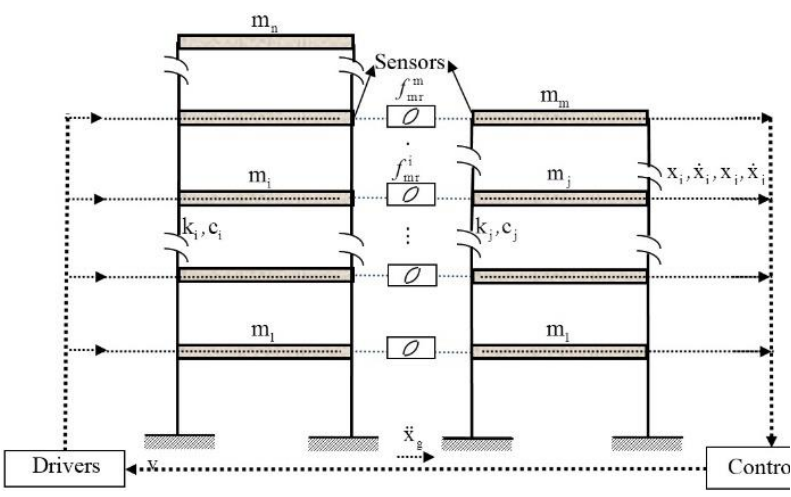

Figure 1: MR dampers located between buildings

Equations of motion of the adjacent buildings are shown in Eqs. (2.1) and (2.2). Equations of motion for the adjacent buildings having flexible columns and mass concentrated at the rigid slabs can be obtained by writing the equilibrium equations from the free body diagram of each of the lumped mass of the building. Eqs. (2.1) and (2.2) can be solved at the same time. For considering semi-active control, first combining these equations can be collected into a convenient matrix form.
Building A:

$$
M_{1} \ddot{X}_{1}+C_{1} \dot{X}_{1}+K_{1} X_{1}=-M_{1} E_{1} \ddot{X}_{g}
$$

Building B:

$$
M_{2} \ddot{X}_{2}+C_{2} \dot{X}_{2}+K_{2} X_{2}=-M_{2} E_{2} \ddot{X}_{g}
$$

Eq. (2.3) can be converted to first order state equations. $\quad c_{d(m, m)}$ and $k_{d(m, m)}$ are the additional damping and stiffness diagonal matrices because of the placement of the MR dampers.

$$
\begin{aligned}
& {\left[\begin{array}{cc}
M_{1} & 0 \\
0 & M_{2}
\end{array}\right]\left\{\begin{array}{l}
\ddot{X}_{1} \\
\ddot{X}_{2}
\end{array}\right\}} \\
& +\left(\left[\begin{array}{cc}
C_{1} & 0 \\
0 & C_{2}
\end{array}\right]+\left[\begin{array}{ccc}
c_{d(m, m)} & 0_{(m, s)} & -c_{d(m, m)} \\
0_{(s, m)} & 0_{(s, m)} & 0_{(s, m)} \\
-c_{d(m, m)} & 0_{(m, s)} & c_{d(m, m)}
\end{array}\right]\right)\left\{\begin{array}{l}
\dot{X}_{1} \\
\dot{X}_{2}
\end{array}\right\} \\
& +\left(\left[\begin{array}{cc}
K_{1} & 0 \\
0 & K_{2}
\end{array}\right]+\left[\begin{array}{ccc}
k_{d(m, m)} & 0_{(m, s)} & -k_{d(m, m)} \\
0_{(s, m)} & 0_{(s, m)} & 0_{(s, m)} \\
-k_{d(m, m)} & 0_{(m, s)} & k_{d(m, m)}
\end{array}\right]\right)\left\{\begin{array}{l}
X_{1} \\
X_{2}
\end{array}\right\} \\
& =\left[\begin{array}{c}
-M_{1} E_{1} \\
-M_{2} E_{2}
\end{array}\right] \ddot{X}_{g}+\left[\begin{array}{l}
P_{1} \\
P_{2}
\end{array}\right] F_{m r}(t)
\end{aligned}
$$

By defining the state vector $X=\left\{X_{1} X_{2} \dot{X}_{1} \dot{X}_{2}\right\}^{T}$,

$$
\begin{aligned}
& \Lambda=\left[\begin{array}{l}
P_{1} \\
0 \\
P_{2}
\end{array}\right] ; \Gamma=\left[\begin{array}{l}
-M_{1} E_{1} \\
-M_{2} E_{2}
\end{array}\right] ; A=\left[\begin{array}{cc}
0_{(n+m) \times(n+m)} & \mathrm{I}_{(n+m) \times(n+m)} \\
-M^{-1} K & -M^{-1} C
\end{array}\right] ; \\
& E=\left[\begin{array}{c}
0_{(n+m) \times 1} \\
M^{-1} \Gamma
\end{array}\right] ; B=\left[\begin{array}{c}
0_{(n+m) \times n_{a}} \\
M^{-1} \Lambda
\end{array}\right]
\end{aligned}
$$

where $n \times 1$ and $m \times 1$ unity matrices are given as $E_{1}$ and $E_{2}$, respectively. $P_{1}$ and $P_{2}$ are dimensional matrices regarding to the number of actuators for the additional dampers. $m$ denotes the lower building's storey levels. Here, an identity matrix is given as I and 0 in matrix $\Lambda$ is a $\left(s \times n_{a}\right)$ matrix containing zero. $F_{m r}=$ $\left[\begin{array}{lllll}f_{m r}^{1} & \ldots & f_{m r}^{i} & \ldots & f_{m r}^{m}\end{array}\right]^{T} \quad$ is control input vector.

$$
\begin{gathered}
\dot{X}=A X+B F_{m r}(t)+E \ddot{X}_{g}(t) ; \\
x=C_{w} X+D_{w} F_{m r} ; y_{m}=C_{m} X+D_{m} F_{m r}+\mathrm{v}
\end{gathered}
$$

In which $y_{m}$ is the vector of measured outputs, $X$ is the regulated output vector. The equations of motion without MR dampers can be noted under only earthquake excitation as

$$
\dot{X}=A X+E \ddot{X}_{g}(t)
$$

Eq. (2.6) defines the uncontrolled adjacent buildings system to compare the behavior of MR dampers installed between both buildings in case. 


\section{MR damper forces}

The modified Bouc-Wen model as shown in Figure 2 is used to simulate the dynamic behaviour of the MR damper as [22]

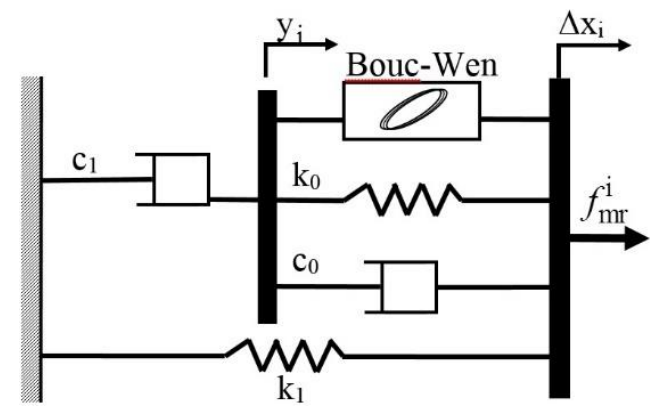

Figure 2: Modified Bouc- Wen model for MR damper [22]

$$
\mathrm{f}_{m r}^{i}=c_{1} \dot{y}_{i}+k_{1}\left(x_{i+n}-x_{i}-x_{0}\right)
$$

where the internal pseudo-displacement, $\dot{y}_{i}$ and the evolutionary variable, $\dot{z}_{d i}$ are given by

$$
\begin{gathered}
\dot{y}_{i}=\frac{1}{\left(c_{0}+c_{1}\right)}\left\{\begin{array}{c}
\alpha z_{d i}+c_{0}\left(\dot{x}_{n+i}-\dot{x}_{i}\right) \\
+k_{0}\left(x_{n+i}-x_{i}-y_{i}\right)
\end{array}\right\} ; \\
\dot{z}_{d i}=-\gamma\left|\dot{x}_{n+i}-\dot{x}_{i}-\dot{y}_{i}\right| z_{d i}\left|z_{d i}\right|^{n-1}-\beta\left(\dot{x}_{n+i}-\dot{x}_{i}-\dot{y}_{i}\right)\left|z_{d i}\right|^{n d} \\
+A_{c}\left(\dot{x}_{n+i}-\dot{x}_{i}-\dot{y}_{i}\right)
\end{gathered}
$$

where $x_{n+i}$ and $x_{i}$ are the displacements of the $i^{\text {th }}$ floor of Building $\mathrm{B}$ and Building $\mathrm{A}$, respectively. The displacement of the MR damper $\Delta x_{i}$ is calculated as the relative displacement amongst two inline adjacent floors (i). $x_{0}$ is the initial displacement of spring of the accumulator stiffness $\mathrm{k}_{1} \cdot \mathrm{k}_{0}$ is the stiffness at large velocities. $c_{0}$ and $c_{1}$ are viscous damping coefficients at large velocities and for force rolloff at low velocities, respectively. $\propto$ is the evolutionary coefficient. Other shape parameters for the hysteresis loop are given as $\gamma, A_{c}, n_{d}$ and $\beta$ in Eq. (3.2). The following three model parameters are based on the command voltage $u$ to the current driver are expressed as follows.

$$
\alpha=\alpha_{a}+\alpha_{b} \mathbf{u}_{i} ; c_{1}=c_{1 a}+c_{1 b} \mathbf{u}_{i} ; c_{0}=c_{0 a}+c_{0 b} \mathbf{u}_{i}
$$

Eq. (3.4) simulates the dynamics involved in both reaching rheological equilibrium and driving the electromagnet in the MR damper. The dynamics are accounted for through the first order filter.

$$
\dot{\mathrm{u}}=-\eta\left(\mathrm{u}_{i}-\mathrm{v}_{i}\right)
$$

where $u_{i}$ is given as the output of a first-order filter which models delay dynamics of the current driver and of the fluid to reach rheological equilibrium. $v_{i}$ is a command input voltage supplied to the damper at the ith floor. $f_{m r}^{i}$ is the damper force at the ith floor level. Parameters of the MR dampers used in this study were obtained by Spencer et al. [21] and are shown in Table 1.

Error! Reference source not found.: Parameters of Bouc-Wen phenomenological model parameters for $1000 \mathrm{kN}$ MR dampers [18,22]

\begin{tabular}{|c|l|c|l|}
\hline Parameter & Value & Parameter & Value \\
\hline$c_{0 a}$ & $\begin{array}{l}50.30 \quad \mathrm{kN} \\
\mathrm{sec} / \mathrm{m}\end{array}$ & $\alpha_{a}$ & $\begin{array}{l}8.70 \\
\mathrm{kN} / \mathrm{m}\end{array}$ \\
\hline$c_{0 b}$ & $\begin{array}{l}48.70 \\
\mathrm{kN} \\
\mathrm{sec} / \mathrm{m} / \mathrm{V}\end{array}$ & $\alpha_{b}$ & $\begin{array}{l}6.40 \\
\mathrm{kN} / \mathrm{m} / \mathrm{V}\end{array}$ \\
\hline$k_{0}$ & $\begin{array}{l}0.0054 \\
\mathrm{kN} / \mathrm{m}\end{array}$ & $\gamma$ & $496.0 \mathrm{~m}^{-2}$ \\
\hline$c_{1 a}$ & $\begin{array}{l}8106.2 \mathrm{kN} \\
\mathrm{sec} / \mathrm{m}\end{array}$ & $\beta$ & $496.0 \mathrm{~m}^{-2}$ \\
\hline$c_{1 b}$ & $\begin{array}{l}7807.9 \\
\mathrm{kN} \\
\mathrm{sec} / \mathrm{m} / \mathrm{V}\end{array}$ & $A_{c}$ & 810.50 \\
\hline$k_{1}$ & $\begin{array}{l}0.0087 \\
\mathrm{kN} / \mathrm{m}\end{array}$ & $n_{d}$ & 2 \\
\hline$x_{0}$ & $0.18 \mathrm{~m}$ & $\eta$ & $195 \mathrm{sec}^{-1}$ \\
\hline
\end{tabular}

\section{Optimal controller design}

For the minimization of semi-active control problems, some optimization methods according to the decided objective function have been applied. $H_{\infty}$ and LQR norms [22] are used to obtain the optimum damper parameters.

\section{1 $\mathrm{H} \infty$ Optimization}

The $H_{\infty}$ norm is achieved to the iterative manner [20]. Hamiltonian matrix in this case can be provided as

$$
\mathrm{H}=\left[\begin{array}{cc}
A+E \mathrm{R}^{-1} D^{T} C_{w} & E \mathrm{R}^{-1} E^{T} \\
-C_{w}^{T}\left(I+D \mathrm{R}^{-1} D^{T}\right) C_{w} & -\left(A+E \mathrm{R}^{-1} D^{T} C_{w}\right)^{T}
\end{array}\right]
$$

where $R=\gamma^{2} I-D^{T} D$. Eigenvalues of the matrix given in Eq. (4.1) are symmetric about the real and imaginary axes with $\mathrm{D}=0$. The following bisection algorithm computes the $H_{\infty}$ norm

(1) Select $\gamma_{u}, \gamma_{l}$ make sure that $\gamma_{l} \leq\left\|\hat{G}_{\infty}\right\| \leq \gamma_{u}$

(2) If $\left(\gamma_{u}-\gamma_{l}\right) / \gamma_{l} \leq$ specified level (Tol.)

Yes Stop $\left(\left\|\hat{G}_{\infty}\right\| \approx \frac{1}{2}\left(\gamma_{u}+\gamma_{l}\right)\right)$

Else jump to Step (3) 
(3) Set $\gamma=\frac{1}{2}\left(\gamma_{u}+\gamma_{l}\right)$ and test if $\left\|\widehat{G}_{\infty}\right\| \leq \gamma$ using $\lambda_{i}(\boldsymbol{H})$

(4) If $\lambda_{i}(\boldsymbol{H}) \mathrm{j} \mathbb{R}$, then set $\gamma_{l}=\gamma$, else set $\gamma_{u}=\gamma$ and go to Step (2)

The $H_{\infty}$ norm to be determined is the resulting $\gamma$. Genetic based optimizer solves the damper parameters then. Note that the controlled output defined in Eq. (2.5) can cover the displacements and velocities of the adjacent buildings. For instance, once the regulated output is chosen as the relative displacement and velocities of the levels of both buildings, matrix $\mathrm{Cw}$ can be selected as

$$
\begin{aligned}
& C_{w}=C_{m}=[\mathrm{I}] ; \\
& D_{w}=D_{m}=[0]
\end{aligned}
$$

where I is a $(2 n+2 m) \times(2 n+2 m)$ identity matrix, 0 and 0 denote as $(2 n+2 m) \times 1$ vector and $(2 n+2 m) \times(m)$ matrix containing zeros, respectively. The scripts of $\mathrm{n}$ and $\mathrm{m}$ denote total DOF of both buildings. The optimization problem is to obtain the optimum bounds of the dampers that minimize $H_{\infty}$ in GA used.

\subsection{LQR Optimization}

The clipped-optimal control method is to solve an optimal control problem and to calculate the optimum force. For this purpose, LQR and $\mathrm{H}_{2} / L Q G$ strategies are common in optimal control problems. Firstly, a LQR algorithm with full state feedback is employed in this study. For designing a LQR controller, the aim is to minimize the quadratic performance index $J=\frac{1}{2} \int_{0}^{\infty}\left[x^{T} \boldsymbol{Q} x+F_{m r}^{T} \boldsymbol{R} F_{m r}\right] d_{t}$ subject to state Eq. (2.5) [23]. Here, both $\boldsymbol{Q}$ positive semi-definite state and $\boldsymbol{R}$ the positive control input weighting matrices are for the vector of regulated responses, $x$ in Eq. (2.5) and of control forces, $F_{m r}$ respectively. Optimal control force vector can be written as [24-25]

$$
f_{d}=-B^{T} \mathbf{R}^{-1} P X=-\mathbf{K} X
$$

where $\mathrm{P}$ is the solution of the algebraic Riccati equation as shown in Eq. (4.4).

$$
P A+A^{T} P+C_{w}^{T} \mathrm{Q} C_{w}-P B \mathrm{R}^{-1} B^{T} P=0
$$

The control input is a vector, i.e. $f_{d}=$ $\left[\begin{array}{llll}f_{d 1} & \ldots & f_{d i} & f_{d m}\end{array}\right]^{T}$ and $=[R] . \quad \boldsymbol{K}$ is the full state feedback gain matrix of the stable regulator problem. However, the number of sensors should be limited for economical reasons, the need of the output feedback, where not all states are available, is more pronounced [20].

\subsection{LQG Optimization}

Many positions in realistic systems are not simply computable. The controller in Eq. (4.3) is not implemental without the full state measurement $[23,26]$. Hence, in this study the results are compared with the corresponding LQR controller. A state estimate is shown as $\hat{X}$ that $\mathrm{f}_{d}=-\mathbf{K} \hat{X}$ stands optimal based on the capacities [23]. An infinite performance directory is selected as $J=\lim _{\tau \rightarrow \infty} \frac{1}{\tau} E\left[\int_{0}^{\tau}\left[y_{m}^{T} \mathbf{Q} y_{m}+\right.\right.$ $\left.\left.F_{m r}^{T} \mathbf{R} F_{m r}\right] d_{t}\right]$. Both $\mathrm{Q}$ and $\mathrm{R}$ weighting matrices are for the vector of measured responses, $y_{m}$ in Eq. (2.5) and of control forces, $F_{m r}$ respectively.

For design purposes, independent Gaussian white noise processes with $S_{\ddot{x}_{g} \ddot{x}_{g}} / S_{v_{i} v_{i}}=\gamma_{g}=50$ is used statistically inhere as the measurement noise is distributed identically. Here, $S_{v_{i} v_{i}}$ and $S_{\ddot{x_{g}} \ddot{x}_{g}}$ are the measurement noise and the auto spectral density function of ground acceleration, respectively. The nominal controller is represented as [27]

$$
\begin{gathered}
\mathbf{Q}=\operatorname{diag}\left[\begin{array}{ll}
K & M
\end{array}\right] ; \\
\mathbf{R}=r \Lambda^{T} K \Lambda \\
\dot{\hat{X}}=\left(A-L_{g} C_{m}\right) \hat{X}+L_{g} y_{m}+\left(B-L_{g} D_{m}\right) F_{m r} ; \\
L_{g}=\left(C_{m} S\right)^{T}
\end{gathered}
$$

The solution of the algebraic Ricatti equation is given in Eq. (4.8) denoting as S. $\hat{X}$ denotes the optimal estimate of the state space vector, $X$. Based on selected displacement and velocity measurements, to estimate the states a Kalman filter is used. To gain an approximately desired control force, $f_{d}$ a force feedback loop is appended for inducing the MR device. A linear optimal controller $K_{c}(s)$ is designed that delivers the desired control force $f_{d}$, according to the measured responses $y_{m}$, and the measured force, $F_{m r}$ as given in Eq. (4.8). The Laplace transform denotes as $L($.$) . Despite the controller$ $K_{c}(s)$ can be received from a range of synthesis methods, the $H_{2} / L Q G$ strategies are synthesized herein because of their successful engineering control applications [26,28]. Note that the damper is driven by the applied command input voltage, 
v. The states i.e. $\left(x, y, z_{d}, u\right)$ are obtained via integration of Eqs. (2.5), (3.2) and (3.4) with MATLAB module ode45 based on the 4 th $/ 5$ th order Runge-Kutta method. Then, available damper force, $\quad F_{m r}=\left[\begin{array}{lllll}f_{m r}^{1} & \ldots & f_{m r}^{i} & \ldots & f_{m r}^{m}\end{array}\right]^{T}$ and the desired force $f_{d}$ are obtained via Eqs. (3.1) and (4.3), respectively.

$$
\begin{gathered}
0=S A^{T}+A S-S C_{m}^{T} C_{m} S+\gamma_{g} E E^{T} \\
f_{d}=\mathrm{L}^{-1}\left\{-\mathrm{K}_{c}(\mathrm{~s}) \mathrm{L}\left(\left[\begin{array}{c}
y_{m} \\
F_{m r}
\end{array}\right]\right)\right\}
\end{gathered}
$$

\subsection{CVL control}

The schematic for implementations of LQR-CVL and LQG-CVL are illustrated in Figure 3. Capsizing the damper dynamics to provide command voltage of a desired force is unfeasible from Eqs. (3.2), (3.3) and (3.4). The first method is based on LQR-CVL and the second method is based on $\mathrm{H}_{2} / L Q G-C V L$. Hence, two methods are approached in order to provide the voltage (v) as explained below. The applied voltage is established after computation of the optimal control force by a predefined control algorithm according to feedback data and measurement of the damper force at each time in order to approach the MR damper control force to the desired optimal force.

Figure 4 shows a block diagram of the clipped optimal semi-active control system. The feedback for the controller is based on displacement

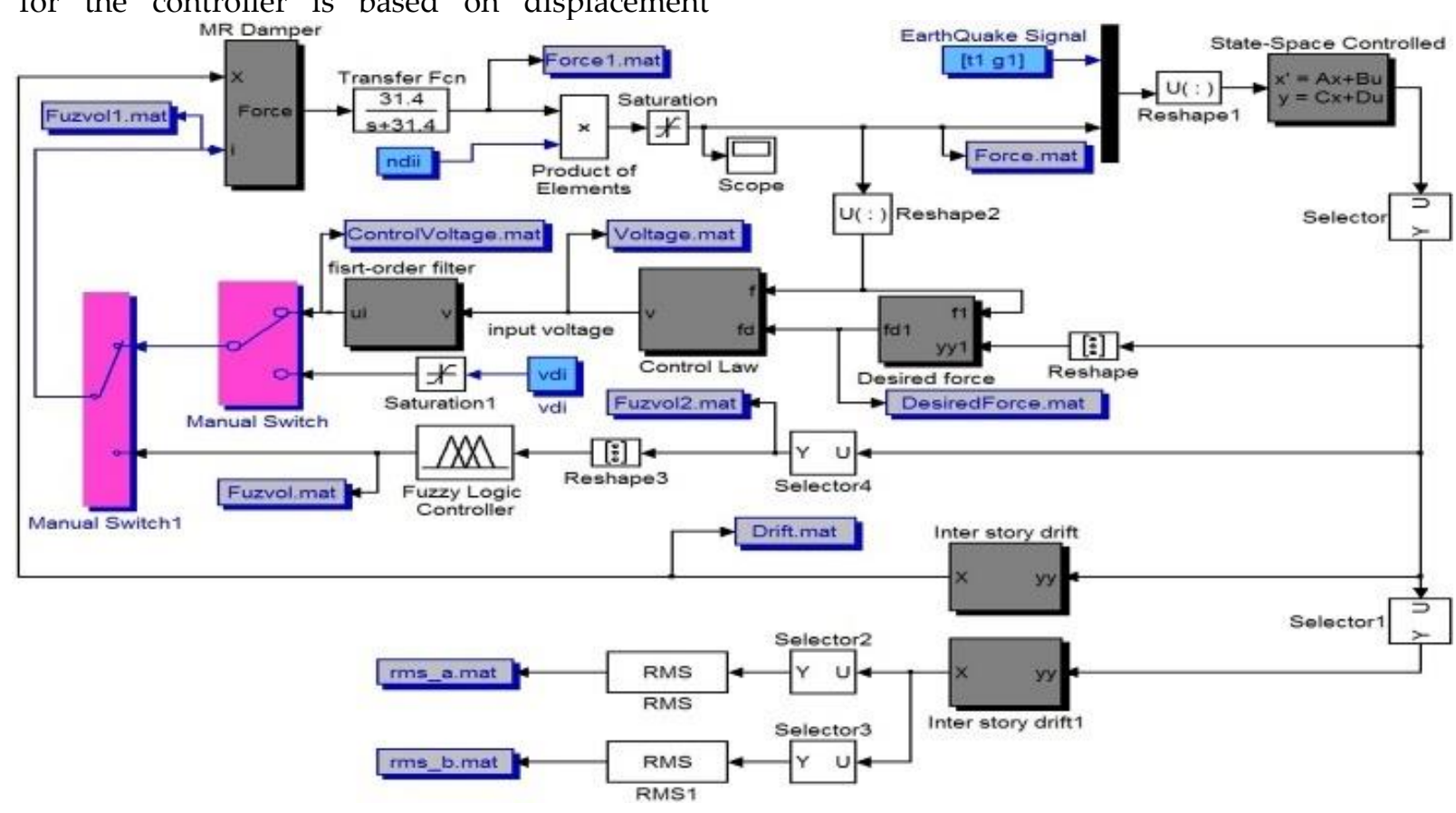

Figure 4: Block diagram of semi-active control mechanism using $H_{2} / L Q G$ controller [9-10] measurements. The input voltage, $\mathrm{v}$, to the below. If these two forces are equal then the chosen voltage is stable. If the absolute total of MR damper force is below from the total of the considered optimal control force and both of them have the same sign, the chosen voltage should be improved to its desired highest value. Else, the input voltage is set to zero.

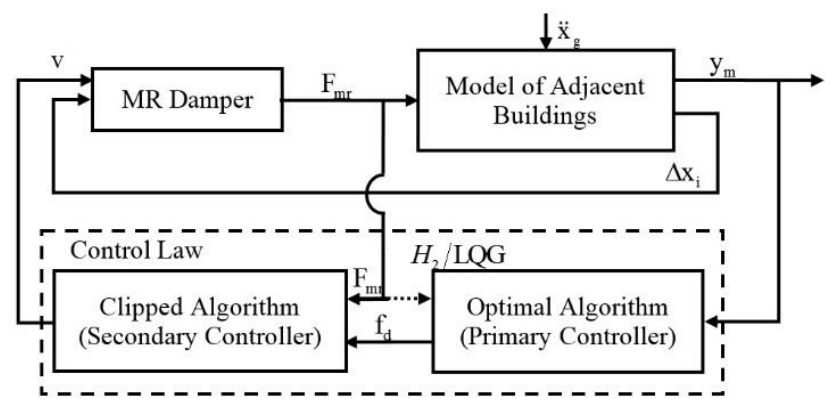

Figure 3: Semi-active control block diagram of LQR-CVL and LQG-CVL [9]

The following equation summarizes clippedoptimal method.

$$
v=V_{\max } \mathrm{H}\left\{\left(f_{d}-F_{m r}\right) F_{m r}\right\}
$$
that is related with the capacity of magnetic field in MR damper and $\mathbf{H}\{$.$\} is the Heaviside$ function. The voltage applied to the MR damper should be $V_{\max }$ when $\mathbf{H}\{$.$\} is greater than zero.$ Otherwise, the command voltage is set to zero. damper is obtained using the CVL as described

where $V_{\max }$ shows the maximum applied voltage 
CBÜ Fen Bil. Dergi., Cilt 13, Sayı 1, 2017, 1-13 s

\section{Numeric Computing}

A numerical example for adjacent buildings is computed on i7-2630QM @2.9 GHz computer running MATLAB R2011b. The MATLAB numeric calculating setting is combined into the SIMULINK block to put on either LQR or $\mathrm{H}_{2} / L Q G$ controller.

\subsection{Numerical Parameters}

A system of MR dampers between different sizes buildings is considered to obtain the optimal semi-active control strategies. Building A is a 20storey shear building given in Bharti et al. [17] and Ok et al. [18]. A 10-storey building discussed in Pourzeynali et al. [29] is taken as Building B. The adjacent buildings are subjected to four earthquake ground motions El-Centro 1940, Kobe 1995 scaled to $0.8 \mathrm{~g}$ and $0.3 \mathrm{~g}$, Sakarya 1999 and Loma Prieta 1989. The structural parameters are given for adjacent buildings in Table 2 .

\subsection{Results of System}

Figure 5 shows the time response histories for the top floor displacement of each building based on the considered four control strategies under the four different earthquakes and compared to uncontrolled case. In time variation responses, the Kobe 1995 earthquake scaled to $0.3 \mathrm{~g}$ is used in order to compare explicitly with other earthquakes considered in this study. As shown in Figure 5 (a), passive-on and semi-active based on both the LQR and LQG norms result in good agreement compared to passive-off under ElCentro 1940 and Sakarya 1999 earthquakes while all control strategies have the same trend in Kobe 1995 and Loma Prieta 1989 ground motions.

It is observed from Figure 5 (b), that all control strategies reduce the upper level displacement of Building B with all the considered earthquakes. In terms of reduction of displacement responses, the performance of the control strategies in the lower building (Building B) is better than the higher building (Building A). Figure 6 indicates the time-histories of the upper level acceleration of Building A and Building B. The results in Figure 6 (a) indicate that for all control strategies the overall trend is similar to the uncontrolled case in Building A.

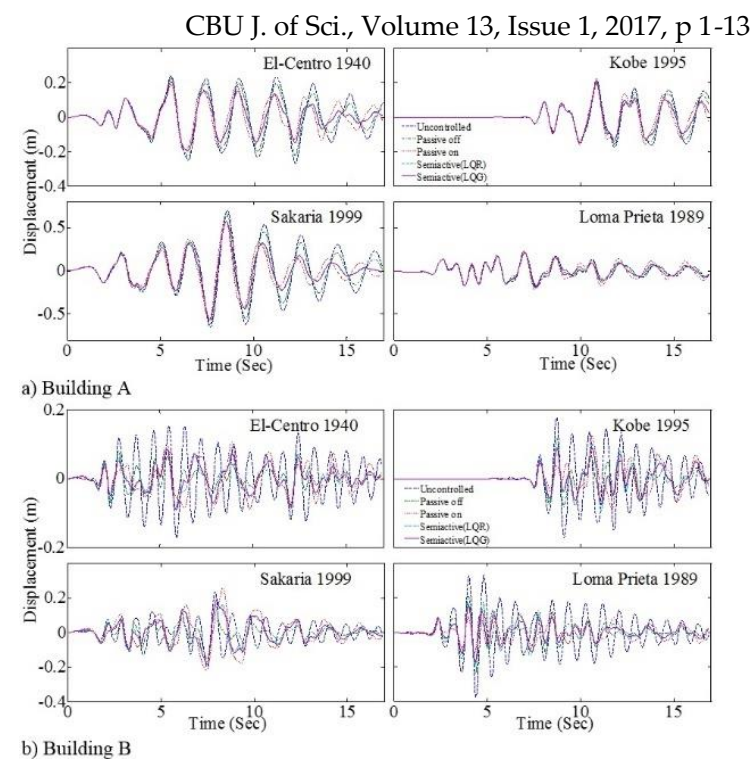

Figure 5: Response of top floor disp. of a) Building A b) Building B

Figure 6 (b) shows that semiactive controller based on LQG norm is effective in response mitigations for the lower building. The acceleration response reduction of Building B is higher under semiactive compared to passive-on strategy, except that under the 1999 Sakarya earthquake semiactive has the same trends with passive-off and on strategies.

Error! Reference source not found.: The structural parameters of the related example [9]

\begin{tabular}{|c|c|c|c|c|c|c|}
\hline \multirow[b]{2}{*}{ No } & \multicolumn{3}{|c|}{ Building A } & \multicolumn{3}{|c|}{ Building $B$} \\
\hline & $m_{i}$ & $\begin{array}{c}k_{i}\left(10^{6}\right) \\
k N / m\end{array}$ & $\begin{array}{l}c_{i}\left(10^{3}\right) \\
k N \text { sec } \\
/ m\end{array}$ & $m_{i}$ & $\begin{array}{c}k_{i}\left(10^{5}\right) \\
k N / m\end{array}$ & $\begin{array}{l}c_{i}\left(10^{3}\right) \\
k N \text { sec } \\
/ m\end{array}$ \\
\hline 1 & 800 & 1.4 & 4.375 & 215 & 4.68 & 1.676 \\
\hline 2 & 800 & 1.4 & 4.375 & 201 & 4.76 & 1.648 \\
\hline 3 & 800 & 1.4 & 4.375 & 201 & 4.68 & 1.585 \\
\hline 4 & 800 & 1.4 & 4.375 & 200 & 4.5 & 1.585 \\
\hline 5 & 800 & 1.4 & 4.375 & 201 & 4.5 & 1.539 \\
\hline 6 & 800 & 1.4 & 4.375 & 201 & 4.5 & 1.539 \\
\hline 7 & 800 & 1.4 & 4.375 & 201 & 4.5 & 1.539 \\
\hline 8 & 800 & 1.4 & 4.375 & 203 & 4.37 & 1.539 \\
\hline 9 & 800 & 1.4 & 4.375 & 203 & 4.37 & 1.099 \\
\hline 10 & 800 & 1.4 & 4.375 & 176 & 3.12 & 1.146 \\
\hline 11 & 800 & 1.4 & 4.375 & - & - & - \\
\hline 12 & 800 & 1.4 & 4.375 & - & - & - \\
\hline 13 & 800 & 1.4 & 4.375 & - & - & - \\
\hline 14 & 800 & 1.4 & 4.375 & - & - & - \\
\hline 15 & 800 & 1.4 & 4.375 & - & - & - \\
\hline 16 & 800 & 1.4 & 4.375 & - & - & - \\
\hline 17 & 800 & 1.4 & 4.375 & - & - & - \\
\hline 18 & 800 & 1.4 & 4.375 & - & - & - \\
\hline 19 & 800 & 1.4 & 4.375 & - & - & - \\
\hline 20 & 800 & 1.4 & 4.375 & - & - & - \\
\hline
\end{tabular}





b) Building B

Figure 6: Time response of top floor acc. a) Building A b) Building B

Although the response history of the top floor acceleration in the higher building is similar in passive-off and passive-on strategies, a comparative performance of the four strategies in Building B can be slightly observed in terms of acceleration responses. The response histories of the normalized base shear of both buildings are investigated in Figure 7.

The base shear is normalized with the corresponding building weight. Therefore, the normalized base shear response of Building $\mathrm{A}$ is explicitly smaller than the normalized base shear response of Building B. Further, Figure 7 (a) indicates that semiactive controllers are in good agreement in the mitigation of the base shear. All controllers are showing better performance compared to the uncontrolled case in Kobe 1995 and El-Centro 1940 earthquakes. Although the MR dampers work as passive devices with the maximum damper command voltage $(6 \mathrm{~V})$ under passive-on strategy, the response histories in terms of the normalized base shear in Figure 7 (a) are almost matching with the uncontrolled case.

It is observed from Figure 7 (b), increase in base shear response is noted for Building B under passive-on strategy for Sakarya 1999 earthquake while all control strategies exhibit better control performance for the other three earthquakes. Another comparative performance of the four control strategies is conducted in terms of the maximum displacement acceleration and storey shear force based on the storey levels of both buildings. Figure 8 shows the peak floor displacement of Building A and Building B.
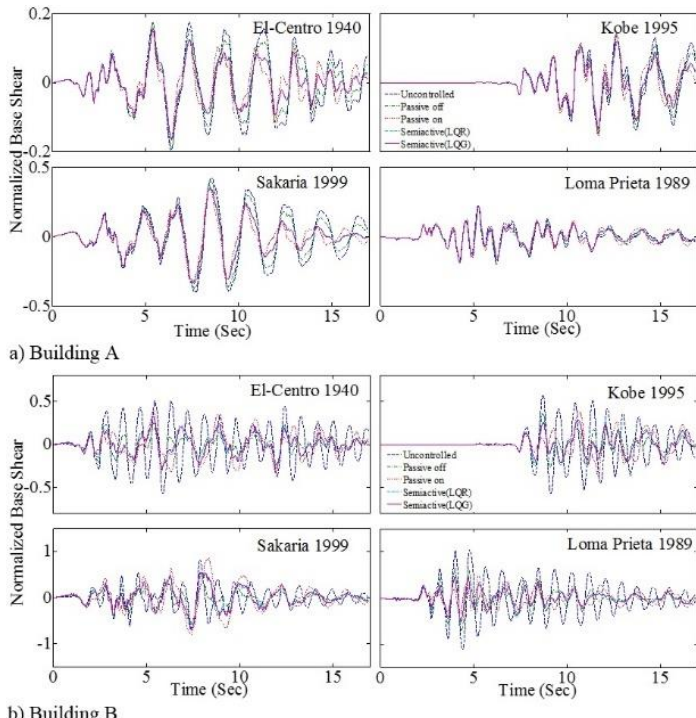

Figure 7: History of base shear of a) Building A

b) Building $B$

The displacement response mitigation for the higher floors of Building B is higher under semiactive associated in passive control strategies and the uncontrolled case. Figure 9 shows the peak floor acceleration based on storey levels. It is observed from Figure 9 (a), that the control strategies are not showing better results compared to the uncontrolled case based acceleration reduction for the higher building (Building A). In higher floors, all control strategies subjected to an increase in acceleration response during Kobe 1995 earthquake. On the other hand, all control strategies in acceleration response reduction for Building $B$ are effective as depicted through Figure 9 (b).
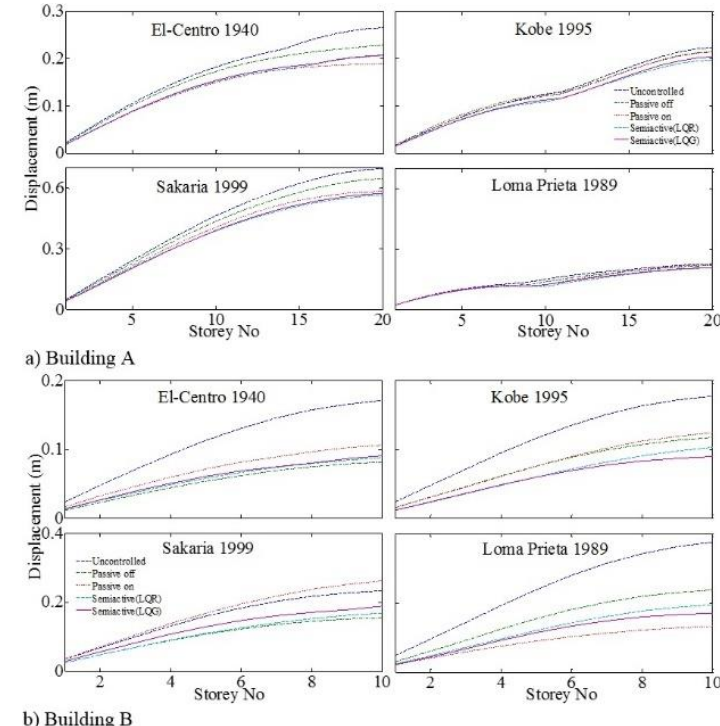
Figure 8: Peak floor disp. of a) Building A

b) Building $B$

Semiactive controller based on LQR is showing better mitigation than semiactive based on $\mathrm{H}_{2} / L Q G$ for Building B. The acceleration reduction of the shorter building (Building $B$ ) is higher than the taller building (Building $\mathrm{A}$ ).

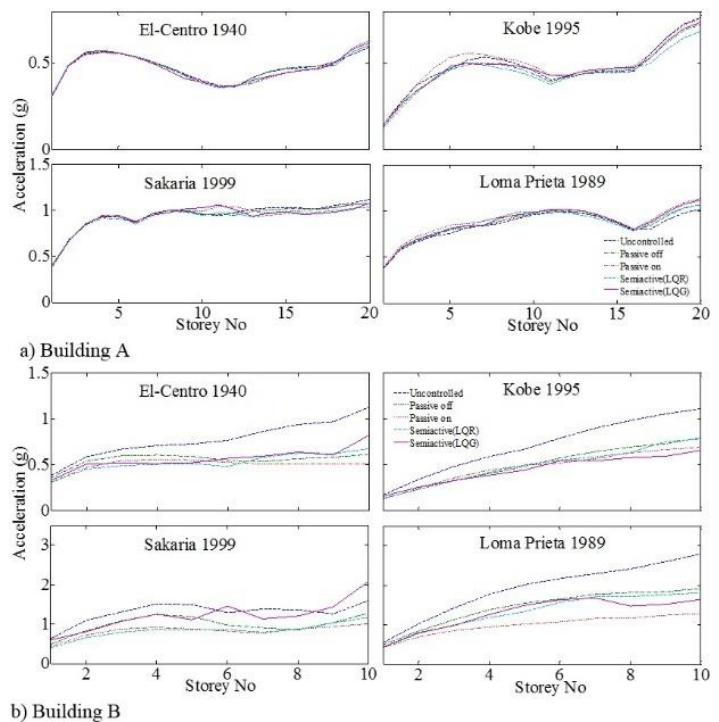

Figure 9: Peak floor acc. of a) Building A b) Building B

Further, it is interesting that passive-on strategy in Figure 9 (b) is showing better response in terms of mitigation of the peak floor acceleration than semiactive and passive-off strategies. Figure 10 shows the four control strategies in terms of storey shear for Building A and Building B. The overall optimum control performance is observed for semiactive controllers for the used earthquakes, especially in Sakarya 1999 for Building A and in Kobe 1995 for Building B.

Passive-on strategy for Building A in Kobe 1995 and Building B in Sakarya 1999 is not effective to reduce the storey shear. For Building A, Kobe 1995 and Loma Prieta 1989 earthquakes show increase in storey shear with increasing storey levels. This is owing to the sway of Building A that is tersely limited by Building B as it's subjected to storey shear above the tenth floor. Hence, this limitation results in an increase in displacement response of Building A under passive-on strategy in Kobe 1995 and Loma Prieta 1989 earthquakes as depicted in Figure 8 (a). In Figure 10 (b) reduction in response for Building $\mathrm{B}$ is observed under all considered earthquakes, except to Sakarya 1999 ground motion.
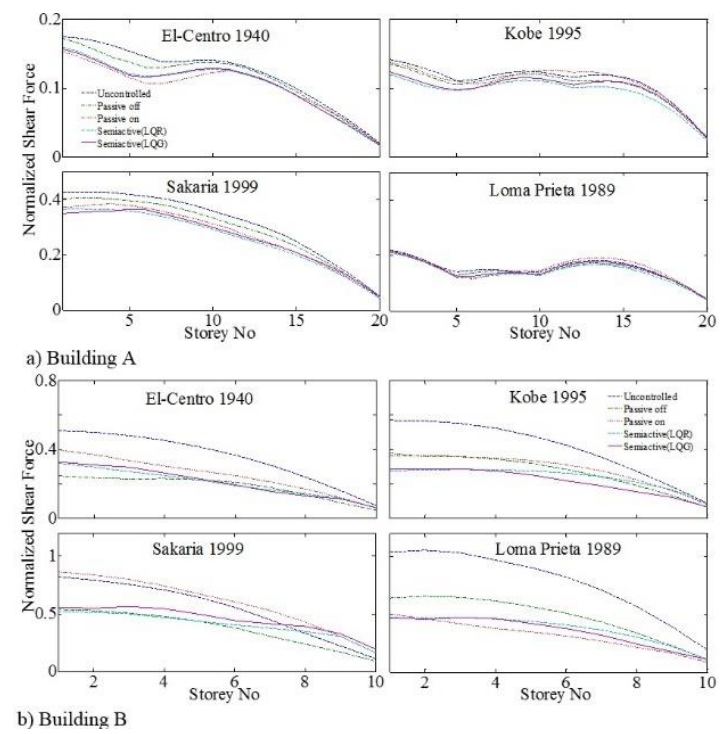

Figure 10: Peak storey shear of a) Building A b) Building B

Passive-on and semiactive controllers showed a better control of response as shown in Figure 10 (b). Hysteresis behaviour of MR damper placed at the 10th storey level between the buildings under four control strategies, namely, passiveoff, passive-on, semiactive-LQR and semiactive$\mathrm{H}_{2} / L Q G$ for the four different earthquakes is shown in Figure 11 and Figure 12.
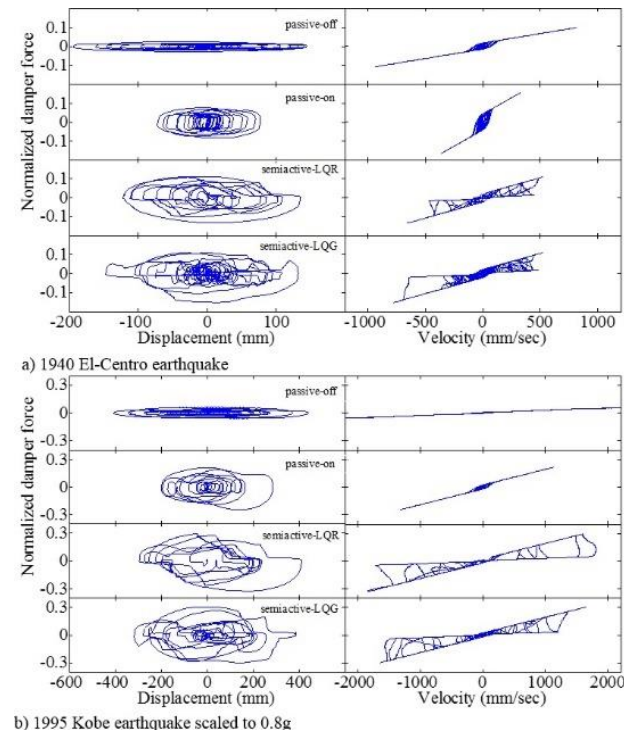

Figure 11: The Performance of MR damper in a) 1940 El-Centro earthquake b) 1995 Kobe earthquake scaled to $0.8 \mathrm{~g}$

There is a substantial energy damping in terms of displacement and velocity responses of MR damper in semi-active based on LQR and LQG 
norms compared to passive-on $\left(\mathrm{V}_{\max }=6 \mathrm{~V}\right)$ and the one called passive-off.
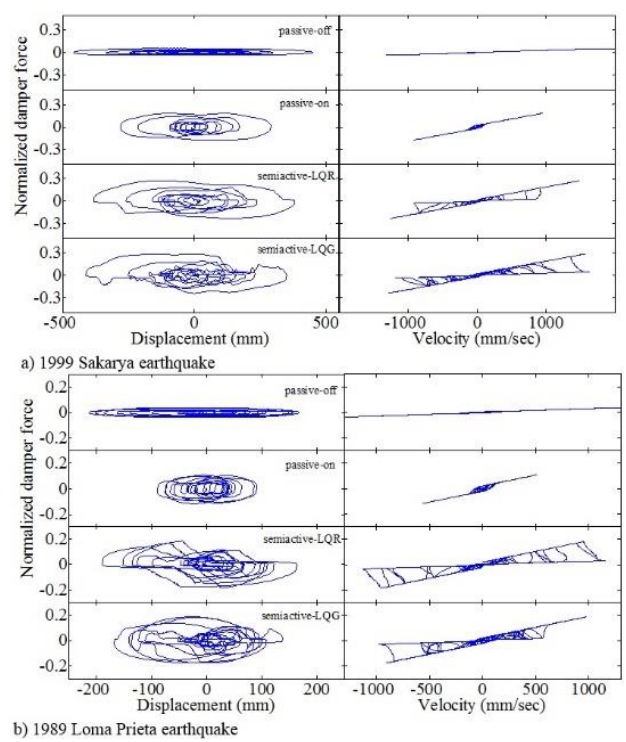

Figure 12: The Behaviour of MR damper under a) 1999 Sakarya earthquake b) 1989 Loma Prieta earthquake

This study also investigated the effect of damper position and command voltage required for MR damper. In order to show the effectiveness of MR dampers for inter-connecting the 10th floors of two buildings having different characteristics, the numerical model is used for the two damper locations and for three parameters of command voltage $(3 \mathrm{~V}, 6 \mathrm{~V}$ and $9 \mathrm{~V})$. The command voltages of MR dampers at each of the ten floors between the buildings are determined by the two proposed methods (LQR and LQG optimizations). The numerical example shows the case that five dampers placed into each floor. Applied input voltages are the same for all 50 dampers in total. The 4th order Runge Kutta method is applied for the purpose of obtaining nonlinear random vibration analyses, while changing the input voltage from 0 to $10 \mathrm{~V}$, which is associated to the capability of the MR dampers for absorbing.

Figure 13 shows the maximum root-mean-square (r.m.s.) values of inter-storey drifts of the coupled systems by varying the uniform input voltage of MR damper under El-Centro 1940 and Kobe 1995 earthquakes.
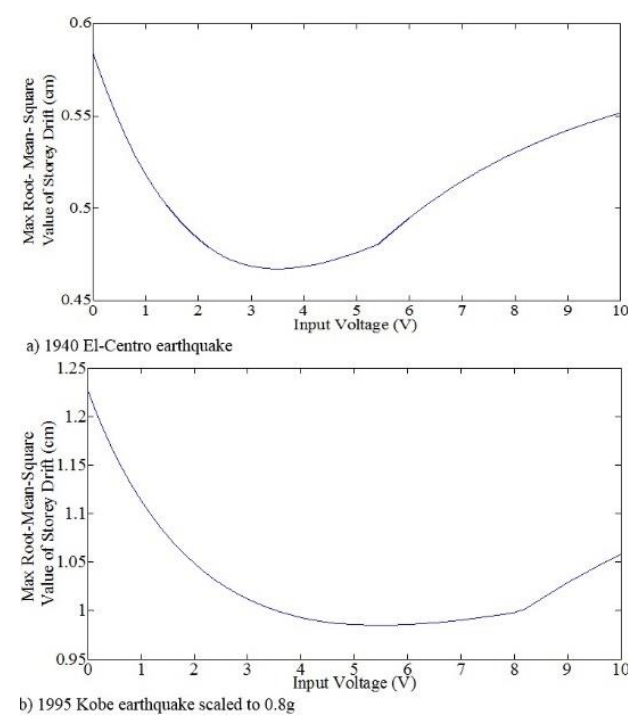

Figure 13: Control performance of MR dampers with uniform input voltages under the 1995 Kobe earthquake scaled to $0.8 \mathrm{~g}$ [9-10]

In Kobe 1995 earthquake, the optimal obtained voltage is $5.6 \mathrm{~V}$ when the $50-\mathrm{MR}$ damper system located uniformly, while the optimal input voltage is $3.1 \mathrm{~V}$ in El-Centro 1940 earthquake. Altering the input voltage can directly lead to change the damping capacity, lacking costly replacements or adjustments. In other words, varying the input voltages of the dampers is achievable to obtain an optimum implementation.

Hence, the results of the peak top floor displacement, acceleration and normalized base shear of the adjacent buildings using the optimum uniform voltage (OUV) is evaluated with the other control strategies used in this study. In Table 3 the overall displacement response reduction with passive-on strategy is as much with semiactive controllers except for passive-off for Building B in El-Centro 1940 earthquake.

Further, the results from Table 3 show that there is not necessary to provide high command voltage for MR dampers and important displacement control is conceivable with less voltage in Building B. Using the optimum uniform voltage (OUV), the significant reduction for both buildings is observed under El-Centro 1940 earthquake although these proposed methods are not effectives in both buildings under Kobe 1995 earthquake. In Table 4, at the top floor drift inter-storey responses the percentage reductions for Building A under 
passive-on strategy as compared to the uncontrolled case are 8.0 under both the earthquakes. For Building B, the corresponding response reductions are 43.9 and 27.9 for ElCentro 1940 and Kobe 1995 earthquakes, respectively.

However, peripheral increase in response is gotten under semiactive controllers $(9 \mathrm{~V})$ for
Building B under El-Centro 1940 earthquake. Table 5 shows that the percentage reductions in peak normalized base shear under passive-on strategy (6V) for both buildings are: 20 and 29.8 and under semiactive based on the reductions are 20 and 44 with El-Centro 1940.

Error! Reference source not found.: Peak top floor displacement under different control strategies

\begin{tabular}{|c|c|c|c|c|c|c|c|c|c|c|c|c|c|}
\hline & \multirow{2}{*}{$\tilde{U}^{\infty}$} & \multirow{2}{*}{ UNC } & \multirow{2}{*}{ Off } & \multicolumn{3}{|c|}{ Passive-on } & \multicolumn{3}{|c|}{ LQR } & \multicolumn{3}{|c|}{$H_{2} / L Q G$} & \multirow{2}{*}{ OUV } \\
\hline & & & & $3 \mathrm{~V}$ & $6 \mathrm{~V}$ & $9 \mathrm{~V}$ & $3 \mathrm{~V}$ & $6 \mathrm{~V}$ & $9 \mathrm{~V}$ & $3 \mathrm{~V}$ & $6 \mathrm{~V}$ & $9 \mathrm{~V}$ & \\
\hline \multirow{2}{*}{ 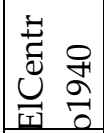 } & A & 26.6 & 22.9 & 20.1 & 19.0 & 19.8 & 21.8 & 21.2 & 20.7 & 21.6 & 20.9 & 20.4 & 20.2 \\
\hline & B & 17.1 & 8.1 & 8.6 & 10.4 & 11.5 & 8.4 & 8.6 & 8.7 & 8.6 & 9.1 & 9.6 & 8.8 \\
\hline \multirow{2}{*}{$\frac{8}{2}$} & A & 61.3 & 59.4 & 57.4 & 58.0 & 59.2 & 56.0 & 55.2 & 54.8 & 57.4 & 56.7 & 56.3 & 58.0 \\
\hline & B & 48.0 & 35.0 & 25.6 & 30.6 & 32.9 & 29.6 & 27.5 & 26.0 & 30.5 & 27.7 & 25.5 & 30.7 \\
\hline
\end{tabular}

Note: the disp. indicated is in $\times 10 \mathrm{~mm}$. UNC: Uncontrolled

Table 1: Peak top floor drift inter-storey under different control strategies

\begin{tabular}{|c|c|c|c|c|c|c|c|c|c|c|c|c|c|}
\hline & \multirow{2}{*}{$\begin{array}{l}\mathscr{J} \\
\tilde{U}\end{array}$} & \multirow{2}{*}{ UNC } & \multirow{2}{*}{ Off } & \multicolumn{3}{|c|}{ Passive-on } & \multicolumn{3}{|c|}{ LQR } & \multicolumn{3}{|c|}{$H_{2} / L Q G$} & \multirow{2}{*}{ OUV } \\
\hline & & & & $3 \mathrm{~V}$ & $6 \mathrm{~V}$ & $9 \mathrm{~V}$ & $3 \mathrm{~V}$ & $6 \mathrm{~V}$ & $9 \mathrm{~V}$ & $3 \mathrm{~V}$ & $6 \mathrm{~V}$ & $9 \mathrm{~V}$ & \\
\hline \multirow{2}{*}{ 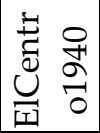 } & A & 0.25 & 0.24 & 0.23 & 0.23 & 0.23 & 0.23 & 0.22 & 0.22 & 0.22 & 0.22 & 0.22 & 0.23 \\
\hline & B & 0.41 & 0.26 & 0.23 & 0.28 & 0.31 & 0.29 & 0.37 & 0.43 & 0.33 & 0.41 & 0.51 & 0.32 \\
\hline \multirow{2}{*}{  } & A & 0.88 & 0.83 & 0.81 & 0.84 & 0.87 & 0.75 & 0.74 & 0.75 & 0.81 & 0.82 & 0.83 & 0.84 \\
\hline & $\mathrm{B}$ & 1.54 & 1.19 & 1.11 & 0.98 & 1.07 & 0.84 & 0.99 & 1.21 & 0.84 & 0.88 & 1.02 & 1.35 \\
\hline
\end{tabular}

Note: Peak top floor drift inter-story indicated is in $\times 10 \mathrm{~mm}$. UNC: Uncontrolled

Error! Reference source not found.: Peak normalized base shear under different control strategies

\begin{tabular}{|c|c|c|c|c|c|c|c|c|c|c|c|c|c|}
\hline & \multirow{2}{*}{$\begin{array}{l}\tilde{E} \\
\tilde{J}\end{array}$} & \multirow{2}{*}{ UNC } & \multirow{2}{*}{ Off } & \multicolumn{3}{|c|}{ Passive-on } & \multicolumn{3}{|c|}{ LQR } & \multicolumn{3}{|c|}{$H_{2} / L Q G$} & \multirow[b]{2}{*}{ OUV } \\
\hline & & & & $3 \mathrm{~V}$ & $6 \mathrm{~V}$ & $9 \mathrm{~V}$ & $3 \mathrm{~V}$ & $6 \mathrm{~V}$ & $9 \mathrm{~V}$ & $3 \mathrm{~V}$ & $6 \mathrm{~V}$ & $9 \mathrm{~V}$ & \\
\hline \multirow{2}{*}{ 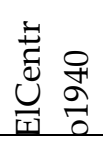 } & A & 0.20 & 0.19 & 0.17 & 0.16 & 0.16 & 0.18 & 0.17 & 0.17 & 0.17 & 0.16 & 0.16 & 0.17 \\
\hline & B & 0.57 & 0.28 & 0.35 & 0.40 & 0.40 & 0.29 & 0.30 & 0.31 & 0.29 & 0.32 & 035 & 0.35 \\
\hline \multirow{2}{*}{ 융 } & $\mathrm{A}$ & 0.40 & 0.40 & 0.41 & 0.42 & 0.43 & 0.39 & 0.39 & 0.38 & 0.38 & 0.37 & 0.37 & 0.42 \\
\hline & B & 1.56 & 1.10 & 0.71 & 0.90 & 1.00 & 0.88 & 0.80 & 0.76 & 0.94 & 0.83 & 0.74 & 0.88 \\
\hline
\end{tabular}

\section{Conclusions}

An optimal design of the nonlinear hysteretic dampers is proposed in order to increase the seismic performance for both buildings. The stochastic responses of adjacent buildings linked with nonlinear dampers are received in an efficient manner with the help of the stochastic linearization method as the optimal design process can avoid numerous nonlinear time-history analyses. Consequently, the numerical example of 10- and 20-storey buildings coupled with MR dampers demonstrate that providing high command voltage is not necessary based on effectiveness of MR dampers. Moreover, the proposed optimal design method can steadily accomplish boosted seismic performance with productivity in economic side.

\section{References}

[1] Yang, Z.; Xu, YL.; Lu, XL. Experimental seismic study of adjacent buildings with fluid dampers. Journal of Structural Engineering. 2003; 129(2), 197-205.

[2] Zhang, W.S.; Xu, Y.L. Dynamic characteristics and seismic response of adjacent buildings linked by discrete dampers. Earthquake Engineering \& Structural Dynamics. 1999; 28(10), 1163-1185. 
[3] Zhang, W.S.; Xu, Y.L. Vibration analysis of two buildings linked by maxwell model-defined fluid dampers. Journal of Sound and Vibration. 2000; 233(5), 775-796.

[4] Zhu, H.P.; Ge, D.D.; Huang, X. Optimum connecting dampers to reduce the seismic responses of parallel structures. Journal of Sound and Vibration. 2011; 330(9), 1931-1949.

[5] Bhaskararao, A.V.; Jangid, R.S. Seismic analysis of structures connected with friction dampers. Engineering Structures. 2006a; 28(5), 690-703.

[6] Bhaskararao, A.V.; Jangid, R.S. Seismic response of adjacent buildings connected with friction dampers. Bulletin of Earthquake Engineering. 2006b; 4(1), 43-64.

[7] Hadi, M.N.S.; Uz, M.E. Investigating the optimal passive and active vibration controls of adjacent buildings based on performance indices using genetic algorithms. Journal of Engineering Optimization. 2014; 1-22.

[8] Ng, C.L.; Xu, Y.L. Seismic response control of a building complex utilizing passive friction damper: Experimental investigation. Earthquake Engineering \& Structural Dynamics. 2006; 35(6), 657-677.

[9] Uz, M.E. Optimum design of semi-active dampers between adjacent buildings of different sizes subjected to seismic loading including soil-structure interaction. PhD Thesis, School of Civil, Mining and Environmental Eng., University of Wollongong, Wollongong, Australia, 2013.

[10] Uz, M.E.; Hadi, M.N.S. Optimal design of semi active control for adjacent buildings connected by MR damper based on integrated fuzzy logic and multiobjective genetic algorithm. Journal of Engineering Structures. 2014; 69, 135-148.

[11] Xu, Y.L.; Zhang, W.S. Closed-form solution for seismic response of adjacent buildings with linear quadratic gaussian controllers. Earthquake Engineering \& Structural Dynamics. 2002; 31(2), 235-259.

[12] Ying, Z.G.; Ni, Y.Q.; Ko, J.M. Stochastic optimal coupling-control of adjacent building structures. Computers \& Structures. 2003; 81(30-31), 2775-2787.

[13] Westermo, B. The dynamics of interstructural connection to prevent pounding. Earthquake Engineering and Structural Dynamics. 1989; 18, 687699.

[14] Ni, Y.Q.; Ko, J.M.; Ying, Z.G. Random seismic response analysis of adjacent buildings coupled with non-linear hysteretic dampers. Journal of Sound and Vibration. 2001; 246(3), 403-417.

[15] Yoshida, O.; Dyke, S.J. Seismic control of a nonlinear benchmark building using smart dampers. Journal of Engineering Mechanics. 2004; 130(4), 386-392.

[16] Luco, J.E.; De Barros, F.C.P. Optimal damping between two adjacent elastic structures. Earthquake Engineering \& Structural Dynamics. 1998; 27(7), 649-659.
[17] Bharti, S.D.; Dumne, S.M.; Shrimali, M.K. Seismic response analysis of adjacent buildings connected with MR dampers. Engineering Structures. 2010; 32(8), 21222133.

[18] Ok, S.Y.; Song, J.; Park, K.S. Optimal design of hysteretic dampers connecting adjacent structures using multi-objective genetic algorithm and stochastic linearization method. Engineering Structures. 2008; 30(5), 1240-1249.

[19] Ahlawat, A.S.; Ramaswamy, A. Multiobjective obtimal absorber system for torsionally coupled seismically excited structures. Engineering Structures. 2003; 25, 941-950.

[20] Arfiadi, Y.; Hadi, M.N.S. Optimal direct (static) output feedback controller using real coded genetic algorithms. Computers \& Structures. 2001; 79(17), 16251634.

[21] Spencer, J.B.; Dyke, S.; Sain, M.; Carlson, J. Phenomenological model for magnetorheological dampers. Journal of Engineering Mechanics. 1997; 123(3), 230-238.

[22] MATLAB, ed. Natick, MA: The Math Works, Inc., R2011b.

[23] Levine, W.S.; Athans, M. On the determination of the optimal constant output feedback gains for linear multivariable systems. IEEE Transactions on Automatic Control. 1970; 15(1), 44-48.

[24] Lewis, F.; Syrmos, V. Optimal control. John Wiley \& Sons, New York, 1995.

[25] Motra, G.B.; Mallik, W.; Chandiramani, N.K. Semiactive vibration control of connected buildings using magnetorheological dampers. Journal of Intelligent Material Systems and Structures. 2011; 22(16), 18111827.

[26] Abdel Raheem, S.; Hayashikawa, T.; Dorka, U. Ground motion spatial variability effects on seismic response control of cable-stayed bridges. Earthquake Engineering and Engineering Vibration. 2011; 10(1), 3749.

[27] Yoshida, O.; Dyke, S.J.; Giacosa, L.M.; Truman, K.Z. Experimental verification of torsional response control of asymmetric buildings using MR dampers. Earthquake Engineering \& Structural Dynamics. 2003; 32(13), 2085-2105.

[28] Spencer, J.B.F.; Suhardjo, J.; Sain, M.K. Frequency domain optimal control strategies for aseismic protection. Journal of Engineering Mechanics. 1994; 120(1), 135-158.

[29] Pourzeynali, S.; Lavasani, H.H.; Modarayi, A.H. Active control of high rise building structures using fuzzy logic and genetic algorithms. Engineering Structures. 2007; 29(3), 346-357. 


\section{Appendix I- Notations}

A = system matrix in state space equation

$\mathrm{A}_{\mathrm{c}} \quad=$ hysteresis loop parameters

a $=$ constant value

$\mathrm{a}_{\mathrm{j}} \quad=$ each random number $(\mathrm{j}=1,2, .$. popsize $)$ between 0 and 1

$\mathrm{a}_{\mathrm{a} 0}, \mathrm{a}_{\mathrm{b} 0}=$ proportional coefficients of Building $\mathrm{A}$ and Building B, respectively

$\mathrm{B}=$ system matrix in state space equation

$\mathrm{b}_{\mathrm{a} 0}, \mathrm{~b}_{\mathrm{b} 0}=$ proportional coefficients of Building $\mathrm{A}$ and Building B, respectively

$\mathrm{C}=$ damping matrix

$\mathrm{C}_{\mathrm{p}} \quad=$ constant value $(1$ or 2$)$

$\mathrm{C}_{\mathrm{w}} \quad$ = regulation matrix

$\mathrm{C}_{1} \quad=$ damping matrix of Building $\mathrm{A}$

$\mathrm{C}_{2} \quad=$ damping matrix of Building $\mathrm{B}$

$\mathrm{c}_{\mathrm{d}} \quad=$ damping of the damper

$\mathrm{c}_{0} \quad=$ hysteresis loop parameters of MR damper

$\mathrm{c}_{0 \mathrm{a}} \quad=$ hysteresis loop parameters of MR damper

$\mathrm{c}_{0 \mathrm{~b}} \quad=$ hysteresis loop parameters of MR damper

$c_{1}=$ hysteresis loop parameters of MR damper

$\mathrm{c}_{\mathrm{la}} \quad=$ hysteresis loop parameters of MR damper

$\mathrm{c}_{\mathrm{lb}} \quad=$ hysteresis loop parameters of MR damper

$\mathrm{D} \quad=$ zero matrix in Hamiltonian

$\mathrm{D}_{\mathrm{w}} \quad=$ regulation matrix

$\mathrm{d}_{\max } \quad=$ the peak uncontrolled floor drift

$\mathrm{E}=$ system matrix in state space equation

$\mathrm{F} \quad=$ fitness function

$\mathrm{f}_{\mathrm{d}} \quad=$ desired force matrix at the damper

$f_{\mathrm{di}}=$ desired force at the $\mathrm{i}^{\text {th }}$ damper

$\mathrm{f}_{\mathrm{mr}} \quad=$ force matrix at the damper

$\hat{\mathrm{G}}_{\infty} \quad=$ transfer function

$\left\|\hat{\mathrm{G}}_{\infty}\right\| \quad=\mathrm{H}_{\infty}$ norm of $\hat{\mathrm{G}}_{\infty}$

$\mathrm{G}^{\mathrm{p}}$

$\mathrm{g}_{\mathrm{rj}}^{\mathrm{pi}}$

$\mathrm{H}_{2}$

$\mathrm{H}_{\infty}$

$\boldsymbol{H}$

$\mathbf{H}\{\}$

$\mathrm{h}_{\mathrm{j}}$

$\mathrm{i}_{\mathrm{s}}$

I

I, I

J

$=$ Hamiltonian

$=$ Heaviside function in Matlab

$=$ bit string no. $(j+1)$ starting from right

$=$ index

$=$ identity vector

$=(\mathrm{n}+\mathrm{m}) \operatorname{and}(2 \mathrm{n}+2 \mathrm{~m})$ identity matrices, respectively

= objective function
J

$\mathrm{P}$

$\mathrm{R}$

$\mathbf{R}$

$\mathrm{r}_{\mathrm{i}}$ $\mathrm{j}_{\mathrm{s}}$

$\mathrm{K}_{1}$

$\mathrm{K}_{2}$

$\mathrm{k}_{\mathrm{d}}$

$\mathrm{k}_{0}$

$\mathrm{k}_{1}$

$\mathrm{L}_{\mathrm{i}}$

$1_{\mathrm{m}}$

M

$\mathrm{M}_{1}$

$\mathrm{M}_{2}$

$\mathrm{m}$

$\mathrm{m}_{\mathrm{i}}, \mathrm{m}_{\mathrm{j}}$

$\mathrm{m}_{\mathrm{a}}$

$\mathrm{N}_{\mathrm{d}}$

$\mathrm{n}$

$\mathrm{n}_{\mathrm{a}}$

nbits

$\mathrm{n}_{\mathrm{d}}$

$\mathrm{n}_{\mathrm{r}}$

$\mathrm{P}_{\mathrm{i}}$

$P_{1}$

$\mathrm{P}_{2}$

$\mathrm{p}_{\mathrm{c}}$

$\mathrm{p}_{\mathrm{m}}$

\section{Q}

$\mathrm{q}_{\mathrm{j}}$

$R$

$\mathrm{S}_{\ddot{\mathrm{x}}_{\mathrm{g}} \ddot{\mathrm{g}}_{\mathrm{g}}}, \mathrm{S}_{v_{\mathrm{i}} v_{\mathrm{i}}}$

$\mathrm{s}$

$=$ performance index

$=$ index

$=$ stiffness matrix of Building $\mathrm{A}$

$=$ stiffness matrix of Building $\mathrm{B}$

$=$ stiffness of the damper

= hysteresis loop parameters of MR damper

= hysteresis loop parameters of MR damper

$=$ lower bound value of design variable

$=$ length of sub-chromosome

$=$ total mass matrix

$=$ mass matrix of Building $\mathrm{A}$

$=$ mass matrix of Building $\mathrm{B}$

$=$ number of floors in Building $\mathrm{B}$

$=\operatorname{mass}(i=1,2, . ., n)(j=1,2, . ., m)$

$=$ number of measurements

$=$ total number of dampers at all floors

$=$ number of floors in Building $\mathrm{A}$

$=$ number of actuators

$=$ number of bits

= hysteresis loop parameters of MR damper

= random number

$=$ Riccati matrix, matrix of Lyapunov equation

$=$ significant digit

$=$ control force location matrix of Building

A

$=$ control force location matrix of Building $\mathrm{B}$

$=$ crossover rate

$=$ mutation rate

$=$ state weighting matrix

$=$ probability of crossover

=unit matrix having a random coefficient

$=$ scalar control force weighting matrix

$=$ control force weighting matrix

$=$ real number of a design variable

= spectral density function of acceleration and measurement noise

$=$ difference between the number floors of both buildings

$=$ Laplace variable

= time

$\begin{array}{ll}\mathrm{t}_{\mathrm{i}} & =\text { integer mapping of a binary string } \\ \mathrm{U}_{\mathrm{i}} & =\text { upper bound value of design variable }\end{array}$

$\mathrm{u}, \dot{\mathrm{u}}=$ control voltage and output of a first-order filter

$\mathrm{V}_{\max } \quad=$ maximum voltage 
$\mathrm{v} \quad=$ input voltages of the first order filter

$v \quad=$ measurement noise vector

$\ddot{\mathrm{X}}_{\mathrm{g}}=$ acceleration vector of the related earthquake

$\mathrm{x}^{\max }=$ maximum displacement of the uncontrolled system

$\mathrm{x}_{\mathrm{i}}, \dot{\mathrm{x}}_{\mathrm{i}} \quad=$ displacement and velocity of the $\mathrm{i}^{\text {th }}$ floor level, respectively

$\mathrm{x}_{0} \quad=$ initial displacement of the damper

$\mathrm{y}_{\mathrm{m}} \quad=$ vector of measured outputs

$\mathrm{y}_{\mathrm{i}}, \dot{\mathrm{y}}_{\mathrm{i}} \quad=$ internal pseudo-displacement

$\mathrm{z}_{\mathrm{di}}, \dot{\mathrm{z}}_{\mathrm{di}} \quad=$ evolutionary variable

$\alpha, \alpha_{a}, \alpha_{b} \quad=$ hysteresis loop parameters of MR damper

$\alpha_{\mathrm{c}} \quad=$ weighting coefficient (1 or 2 )

$\beta=$ hysteresis loop parameters of MR damper

$\gamma, \gamma_{\mathrm{u}}, \gamma_{1}=\mathrm{a}$ random number, upper bound and lower bound of a positive number

$\omega_{\mathrm{ai}}, \omega_{\mathrm{aj}}=$ structural modal frequencies of modes $i$ $\omega_{\mathrm{bi}}, \omega_{\mathrm{bj}} \quad$ and $j$ of both buildings

$\xi_{\mathrm{ai}}, \xi_{\mathrm{aj}}=$ structural damping ratios for modes $i$ and

$\xi_{\mathrm{bi}}, \xi_{\mathrm{bj}} \quad j$ of both buildings

$\mu \quad=$ constant to scale the fitness function

$\Lambda=$ system matrix in state space equation

$0 \quad$ = zero matrix 